\title{
Detection of Lyme Disease and Q Fever Agents in Wild Rodents in Central Italy
}

\author{
Ilaria Pascucci, Marco Di Domenico, Francesca Dall'Acqua, Giulia Sozio, and Cesare Cammà
}

\begin{abstract}
The maintenance of tick-borne disease agents in the environment strictly depends on the relationship between tick vectors and their hosts, which act as reservoirs for these pathogens. A pilot study aimed to investigate wild rodents as reservoirs for zoonotic tick-borne pathogens (Borrelia burgdorferi sensu lato (s.l.), Coxiella burnetii, Francisella tularensis, and Anaplasma phagocytophilum) was carried out in an area of Gran Sasso e Monti della Laga National Park (Abruzzi Region, central Italy), a wide protected area where, despite sporadic reports of infection in humans and animals, eco-epidemiological data on these diseases are still not available. Rodents were trapped and released at the capture site after the collection of feeding ticks and blood samples. In all, 172 ticks were collected; the most frequent species was Ixodes acuminatus (53\%). Out of 88 tick pools, 11 resulted positive for $C$. burnetii and 13 for B. burgdorferi s.l.; the Borrelia afzelii genospecies was identified in one Ixodes ricinus tick collected from one Apodemus sp. rodent. Out of 143 blood samples, seven Apodemus spp. and five Myodes glareolus were positive for B. burgdorferi s.l. and two Apodemus spp. were positive for $C$. burnetii. All samples (ticks and blood) were negative for $F$. tularensis and A. phagocytophilum. This is the first report of B. burgdorferi s.l. in the environment for Abruzzi Region. Data on the presence of B. burgdorferi s.l. are similar to that observed in other Mediterranean countries. The present work is also the first report of C. burnetii in wild rodents in Italy. C. burnetii infection has been largely investigated in Italy in ruminant farms by serology and molecular methods, but information on ecology and on the wild cycle are still lacking. Further studies including genotyping should be performed and species-specific differences between wild rodent reservoirs of Q fever and Lyme disease agents should be investigated.
\end{abstract}

Key Words: Anaplasma phagocytophilum-Apodemus_Borrelia burgdorferi s.1_—Coxiella burnetii_Francisella tularensis-Ixodidae-Myodes-Reservoir-Ticks-Zoonosis.

\section{Introduction}

$\mathbf{T}$ ICK-BORNE ZOONOTIC DISEASES (TBDs) are those transmitted by ticks, obligate parasites of vertebrate hosts that occasionally bite humans. The maintenance and circulation of TBD agents in the environment strictly depend on the life cycles of tick vectors and their hosts, such as mammals, birds, and reptiles, which act as reservoirs for these pathogens. In the last years, increasing attention has been given to ticks and tick-borne pathogens due to the high number of human clinical cases. Furthermore, several emerging TBDs have been described all over the world, determining an increasing interest in this topic for both research and public health.
Among TBDs, Lyme disease caused by spirochetes of the Borrelia burgdorferi sensu lato (s.1.) complex is documented all over the world and is the most widespread in Italy (Rizzoli et al. 2011). The highest prevalence in ticks is reported in the northeast of the country, where several clinical cases in humans have been described (Ministry of Health [Italy] 2000). Five genospecies (B. afzelii, B. garinii, B. burgdorferi sensu stricto [s.s.], B. bavariensis, and B. spielmanii) are involved in human cases in Europe, whereas the pathogenic role of $B$. lusitaniae, B. valaisiana, and $B$. bissetii is still uncertain (Rizzoli et al. 2011). The persistence of $B$. burgdorferi s.l. in endemic areas depends on the presence of specific hosts. In Europe, three wild rodent species have been recognized as the

\footnotetext{
Istituto Zooprofilattico Sperimentale dell'Abruzzo e del Molise “G. Caporale”, Teramo, Italy.

${ }^{\odot}$ Ilaria Pascucci, et al. 2015; Published by Mary Ann Liebert, Inc. This Open Access article is distributed under the terms of the Creative Commons Attribution Noncommercial License (http://creativecommons.org/licenses/by-nc/4.0/) which permits any noncommercial use, distribution, and reproduction in any medium, provided the original author(s) and the source are credited.
} 
main reservoirs of the rodent-associated genospecies $B$. afzelii and B. burgdorferi s.s. - the wood mouse Apodemus sylvaticus, the yellow necked mouse Apodemus flavicollis, and the bank vole Myodes glareolus (Gern 2008). B. burgdorferi s.l. spirochetes have also been detected in central Italy (Pascucci and Cammà 2010, Ragagli et al. 2011).

Q fever, caused by the bacterium Coxiella burnetii, has been known to be present in Italy since the 1940s (Caporale and Mantovani 1951). Since then, however, only sporadic and scattered serosurveys have been conducted; therefore, limited information is available on the distribution of the etiological agent. Recently, a study on the spread and molecular characterization of the pathogen in a domestic cycle in central Italy revealed novel genotypes circulating in cattle and goats (Di Domenico et al. 2014). However, no investigation was conducted in natural environment and the role of wild cycle in maintaining and spreading of the pathogen is still unknown.

The zoonotic disease tularemia, caused by the bacterium Francisella tularensis, has been known to be present in Italy for several years thanks to reports of clinical cases, mainly in central and northern Italy (Castro et al. 1999). Tularemia is transmitted by ticks and mosquitos by contact with infected animals or by drinking contaminated water. The etiological agent circulates mainly in hares and it causes clinical forms (usually fatal in acute cases), although rodents represent an important reservoir of the pathogen, especially in the aquatic cycle (Greco et al. 1987, Kaysser et al. 2008, Nigrovic and Wingerter 2008, Fabbi et al. 2009).

Another important TBD is human granulocytic anaplasmosis (HGA). This worldwide-emerging tick-borne zoonosis has been reported only recently in Italy in the northeast area of the country (Beltrame et al. 2006). Furthermore, a human pathogenic strain of Anaplasma phagocytophilum has been recently identified in a questing nymph of Ixodes ricinus in northeastern Italy (Baráková et al. 2014). Several studies have recently demonstrated the intraspecific genetic variability of A. phagocytophilum and its association with different reservoir host and tick vector species (Stuen et al. 2013). However, the different role of vertebrate species as competent reservoirs of A. phagocytophilum in Europe needs further clarification, and, in particular, the role played by wild rodents in maintaining the etiological agent in the environment is still debated (Woldehiwet 2006, Baráková et al. 2014).

Given the strict association between TBDs and the natural environment, investigating the role of wild vertebrates as reservoirs is a critical step to understanding the epidemiological cycle of these diseases. In Europe several species of small mammals such as mice (Apodemus spp.) and voles (Microtus spp. and M. glareolus) are recognized as the natural reservoirs of tick-borne bacterial zoonoses, although detailed information on their role in maintaining and spreading the diseases is still poorly known in many areas.
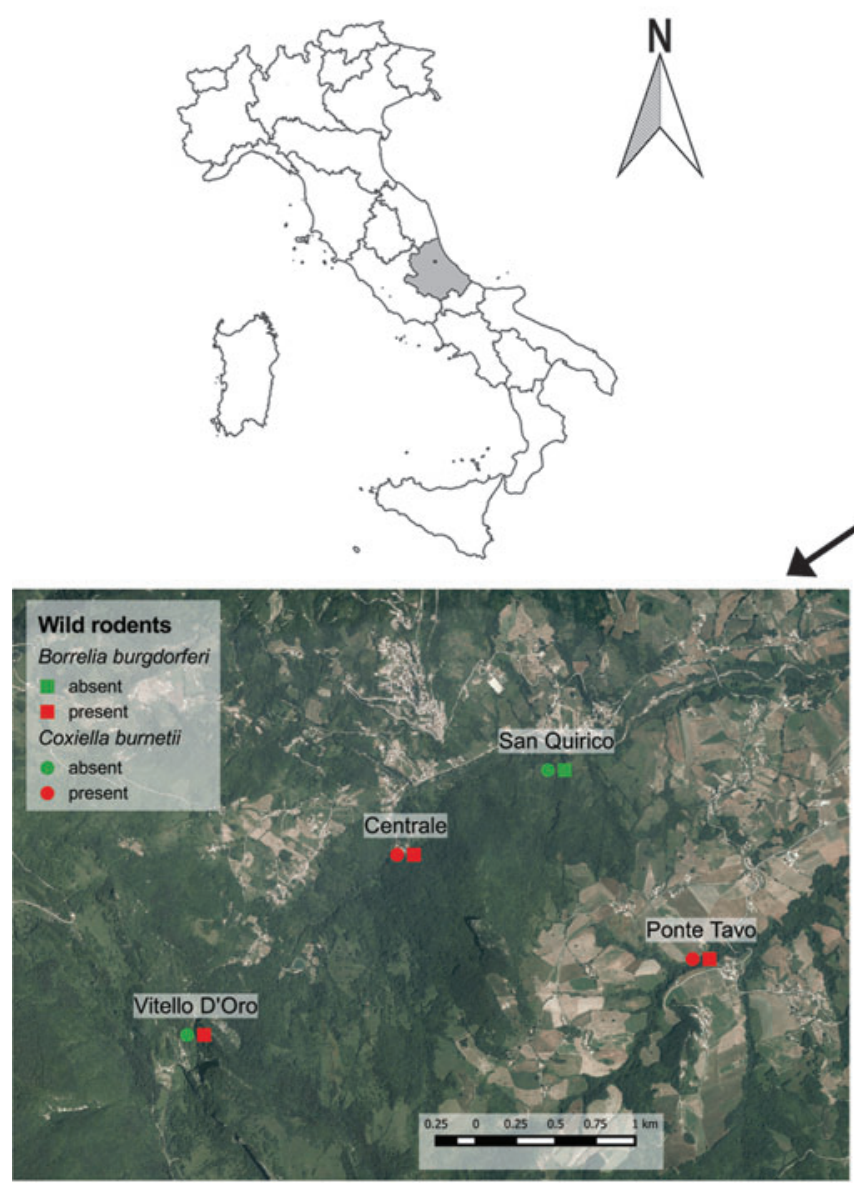
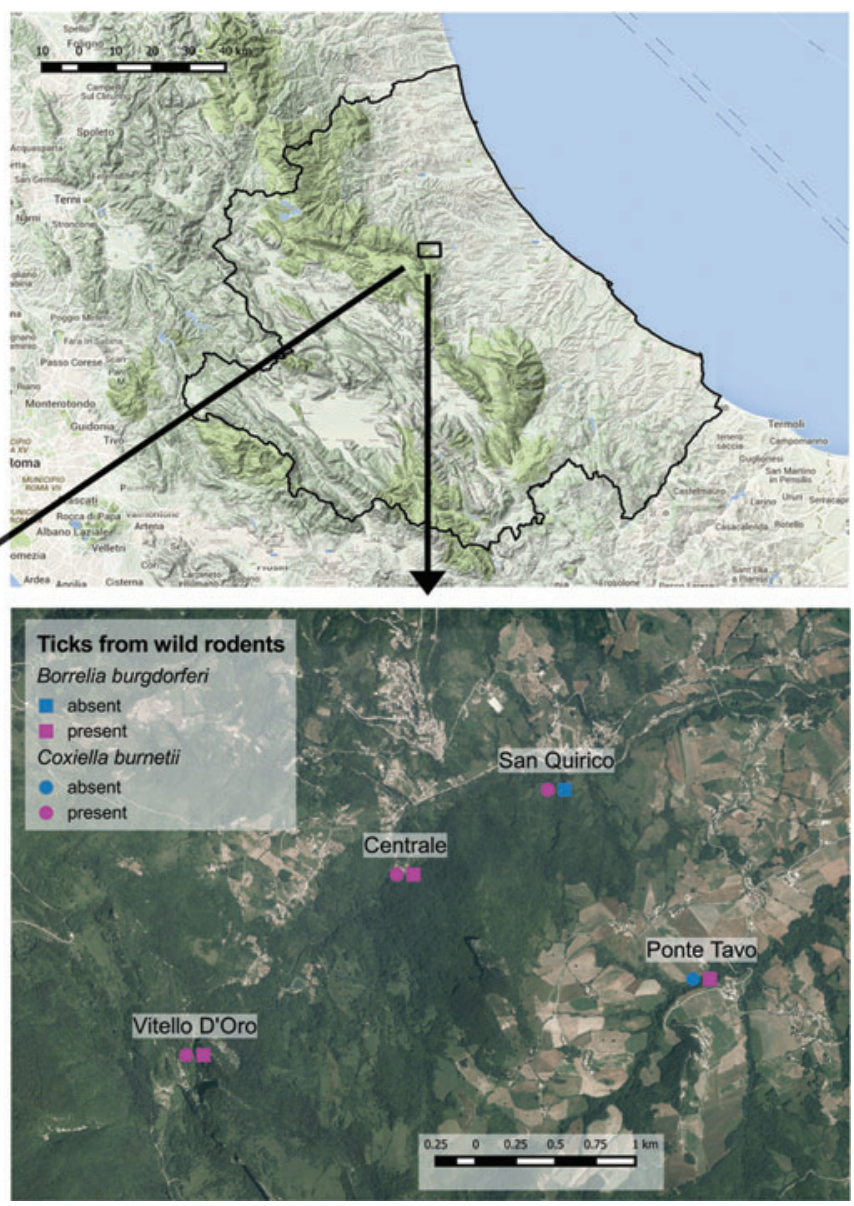

FIG. 1. Location of the study area in "Gran Sasso e Monti della Laga" National Park in Italy with positive sampling sites for the selected pathogens. 


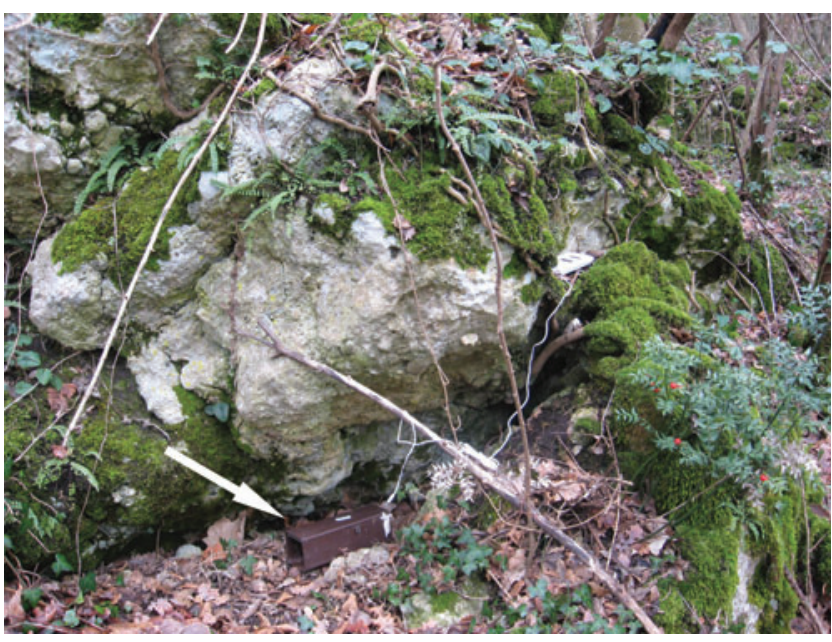

FIG. 2. LOT (Locasciulli Osvaldo Trap, Italy) live trap for wild rodents placed in the wood.

We focused our study on the Abruzzi Region, an area where, despite sporadic reports of TBD infection in humans (Fazii et al. 2000) and animals, epidemiological studies and data on natural reservoirs are still not available. Here we introduce the results of a pilot study aimed to investigate the role of wild rodents as reservoirs for zoonotic tick-borne pathogens (B. burgdorferi s.l., C. burnetii, F. tularensis, and A. phagocytophilum) in a protected area of central Italy.

\section{Materials and Methods}

\section{Study area}

Sampling was conducted in an area of the "Gran Sasso e Monti della Laga" National Park (Fig. 1). It is one of the largest protected areas in Italy, with an area of 150,000 hectares, visited by thousands of people every year. The study was conducted in four sites characterized by mesophilous vegetation, high levels of wild fauna biodiversity and small-stock rural breeding, and elevations between 430 and 642 meters above sea level (a. s. 1.). All these features support a high density of different ixodid tick populations (Manilla 1998) and are potentially associated with circulation of TBD agents.

\section{Rodent sampling}

From February, 2008, to June, 2009, rodents were trapped during 15 capture sessions in four capture sites using a total of 47 Sherman (H.B. Sherman Inc., Tallahassee, FL) and LOT (Locasciulli Osvaldo Trap, Italy) live traps activated for two consecutive nights in each session (Fig. 2). Trapped animals were etherized, identified, and marked by ear-tag (Michel suture clips with an alphanumeric code), and biometric measures were recorded. A few drops of blood were collected from the tail vein and spotted on Whatman FTA gene cards (Whatman Inc., Florham Park, NJ) (Fig. 3). Ticks found on the animals were collected with tweezers and stored in $70 \%$ ethanol (Fig. 4). In the case of recapture of the same animals during subsequent sampling, inspection and tick collection were repeated each time. Blood samples from the rodents, instead, were collected only at the first capture. After these procedures the animals were released at the site of capture.

\section{Laboratory analyses}

Ticks collected from rodents were classified according to the morphological dichotomous key of Manilla (1998). Scanning electron microscopy (SEM) was also used to resolve doubtful morphological identifications.

Blood samples and tick pools of two or three ticks of the same species/genus were tested by real-time PCR to detect the selected TBD agents. DNA extraction from blood spotted on FTA cards was performed using a Maxwell ${ }^{\circledR}$ DNA IQ ${ }^{\mathrm{TM}}$ Casework Sample Kit (Promega) with a Maxwell ${ }^{\circledR} 16$ Instrument (Promega) following the protocol "FTA Blood Card Punches: Genomic DNA." DNA extraction from ticks was carried out using a Maxwell 16 Tissue DNA Purification Kit (Promega). Specific primers and TaqMan probes were used to detect A. phagocytophilum, F. tularensis, and C. burnetii (Table 1). Primers and probe optimal concentrations were determined experimentally for each method. Real-time PCR reactions were prepared using TaqMan ${ }^{\circledR}$ Fast Universal PCR Master Mix (Applied Biosystems) and performed on a 7900HT Fast-Real Time PCR System (Applied Biosystems).
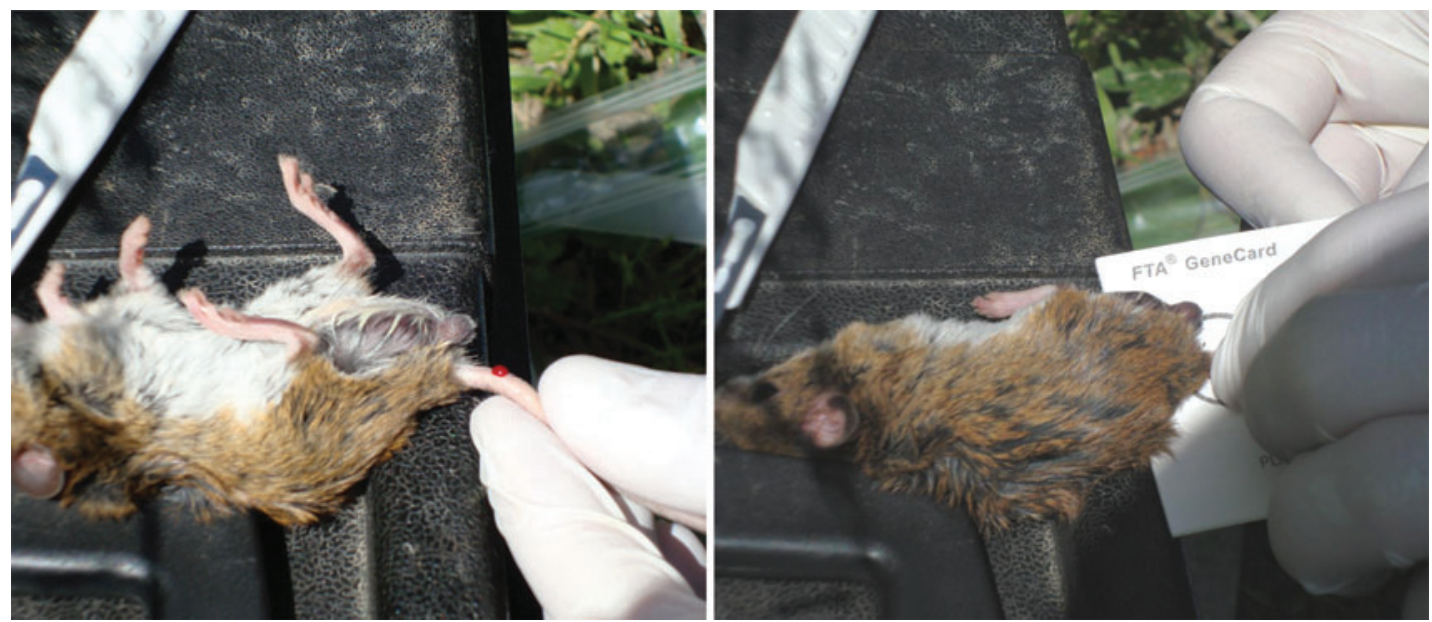

FIG. 3. Collection of blood samples from rodents by FTA gene card (Whatman Inc., Florham Park, NJ). 


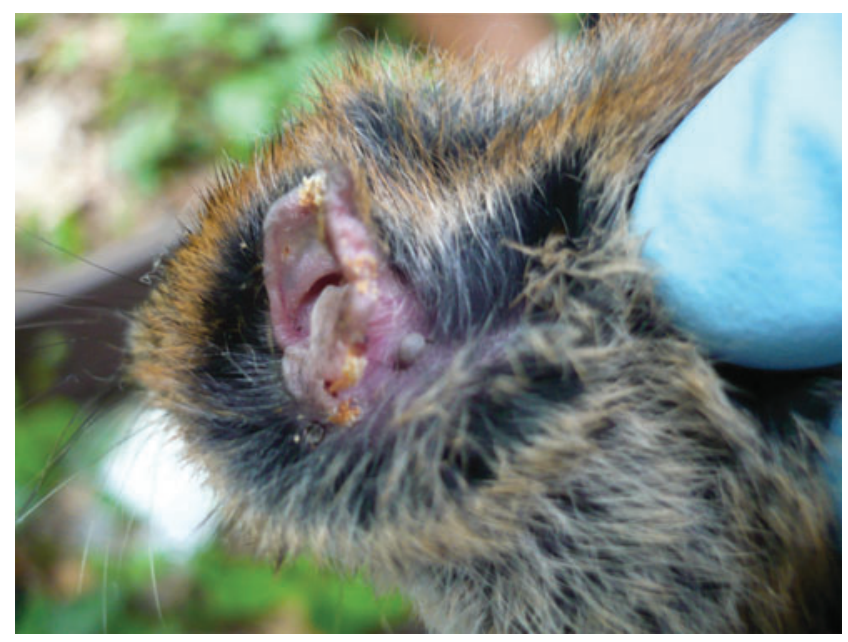

FIG. 4. Ear of a bank vole (M. glareolus) parasitized by an ixodid tick.

To detect B. burgdorferi s.l., a SYBR Green Real Time PCR, followed by a dissociation curve analysis, was carried out using primers described by Rijpkema et al. (1995) (Table 1). Traditional PCR using the same primers was conducted on positive samples for sequencing. PCR products were purified by a QIAquick PCR Purification Kit (Qiagen) and sequenced using a BigDye ${ }^{\circledR}$ Terminator v3.1 Cycle Sequencing Kit (Applied Biosystems) and the 3130XL Genetic Analyzer (Applied Biosystems). Sequences were assembled using Contig Express (Vector NTI suite 9.1; Invitrogen).

\section{Statistical analyses}

Because rodent population size in our study area can be reasonably assumed to be higher than 1000 , we used a beta distribution to estimate the prevalence of infection in the population with a $95 \%$ confidence interval. The estimated infection rate in ticks was calculated as follows according to a binomial distribution:

$$
p=1-(\text { neg } / N)^{\wedge} 1 / k
$$

where $p$ is the estimated probability that a single tick is infected, neg is the number of negative pools, $N$ is the number of tested samples, and $k$ is the number of ticks in each single pool.

\section{Results}

Out of 249 rodent captures, 44 (18\%) were infested by ticks. A total of 172 ticks were collected and identified; the most frequent species were Ixodes acuminatus (53\%), Rhipicephalus turanicus (25.6\%), and I. ricinus (13.4\%) (Table 2). Identification of I. acuminatus was confirmed by SEM (Fig. 5). Other species, such as Dermacentor marginatus, Ixodes hexagonus, Haemaphysalis punctata and Hyalomma spp., were found at a low percentage (0.6-4\%) (Table 2).

$R$. turanicus ticks, mainly constituted by larvae, were found only in summer. I. ricinus specimens were collected during spring and autumn, and they were mainly larvae and nymphs. Specimens of all development stages (female adults, nymphs, and larvae) of I. acuminatus were found in all seasons, but mainly in late spring. Furthermore, for the first time we found a male of I. acuminatus mating a female that was feeding on a rodent. The biology of this endophilous rodentassociated tick species is largely unknown, and to date males were only occasionally detected on mustelids, common predators of wild rodents and voles (Manilla 1998).

Ticks collected from rodents were grouped in 88 pools. Thirteen pools were positive for $B$. burgdorferi s.l. and 11 were positive for $C$. burnetii. Infection rate in ticks was $5.2 \%$ and $4.4 \%$ for B. burgdorferi s.1. and for C. burnetii, respectively. Detailed results of real-time PCR tests on ticks are summarized in Table 3.

Only a sample showing high DNA concentration from one I. ricinus tick collected on an Apodemus sp. individual was sequenced for genotyping. BLASTnt analysis revealed $96 \%$ similarity to B. afzelii strain pK0 (acc. no. NC_008277). Moreover, the same similarity percentage was observed with a sequence of B. afzelii (acc. no. DQ860261) described by (Pecchioli et al. 2007) related to a study conducted on ticks collected in Trento Province (northeast Italy). Other samples

Table 1. Specific Targets for Real-Time PCR

\begin{tabular}{|c|c|c|c|c|}
\hline Pathogen & Sequence & Concentration & Target & Reference \\
\hline \multicolumn{5}{|c|}{ Anaplasma phagocytophilum } \\
\hline Forward & ATGGAAGGTAGTGTTGGTTATGGTATT & $900 \mathrm{nM}$ & \multirow{3}{*}{$m s p 2$} & \multirow{3}{*}{$\begin{array}{l}\text { Courtney } \\
\text { et al. } 2004\end{array}$} \\
\hline Reverse & TTGGTCTTGAAGCGCTCGTA & $900 \mathrm{nM}$ & & \\
\hline Probe & TGGTGCCAGGGTTGAGCTTGAGATTG & $250 \mathrm{nM}$ & & \\
\hline \multicolumn{5}{|c|}{ Francisella tularensis } \\
\hline Forward & ATTACAATGGCAGGCTCCAGA & $300 \mathrm{nM}$ & \multirow{3}{*}{ tul4 } & \multirow{3}{*}{$\begin{array}{l}\text { Versage } \\
\text { et al. } 2003\end{array}$} \\
\hline Revrese & TGCCCAAGTTTTATCGTTCTTCT & $300 \mathrm{nM}$ & & \\
\hline Probe & TTCTAAGTGCCATGATACAAGCTTCCCAATTACTAA & $250 \mathrm{nM}$ & & \\
\hline \multicolumn{5}{|c|}{ Coxiella burnetii } \\
\hline Forward & GATAGCCCGATAAGCATCAAC & $300 \mathrm{nM}$ & \multirow{3}{*}{$\begin{array}{l}\text { IS1111 } \\
\text { sequence }\end{array}$} & \multirow{3}{*}{$\begin{array}{l}\text { Panning } \\
\quad \text { et al. } 2008\end{array}$} \\
\hline Reverse & GCATTCGTATATCCGGCATC & $300 \mathrm{nM}$ & & \\
\hline Probe & TGCATAATTCATCAAGGCACCAATGGT ${ }^{\mathrm{a}}$ & $100 \mathrm{nM}$ & & \\
\hline \multirow{2}{*}{\multicolumn{3}{|c|}{ Borrelia burgdorferi }} & \multirow{3}{*}{$\begin{array}{c}5 S-23 S \\
\text { IGS }\end{array}$} & \multirow{3}{*}{$\begin{array}{l}\text { Rijpkema } \\
\quad \text { et al. } 1995\end{array}$} \\
\hline Forward & & $400 \mathrm{nM}$ & & \\
\hline Reverse & ACCATAGACTCTTATTACTTTGAC & $400 \mathrm{nM}$ & & \\
\hline
\end{tabular}

${ }^{\mathrm{a}}$ Modified (Di Domenico et al. 2014)

IGS, intergenic space. 
Table 2. Tick Species Collected on Wild Rodents

\begin{tabular}{lcc}
\hline Tick species & Tick number & Tick \% \\
\hline Ixodes acuminatus & 92 & $53 \%$ \\
Rhipicephalus turanicus & 44 & $25.6 \%$ \\
Ixodes ricinus & 23 & $13.4 \%$ \\
Ixodes spp. & 7 & $4 \%$ \\
Ixodes hexagonus & 2 & $1.2 \%$ \\
Haemaphysalis punctata & 2 & $1.2 \%$ \\
Dermacentor marginatus & 1 & $0.6 \%$ \\
Hyalomma sp. & 1 & $0.6 \%$ \\
$\quad$ Total & 172 & $100 \%$ \\
\hline
\end{tabular}

were positive for B. burgdorferi s.l.; however, the low DNA concentration made them inadequate for sequencing.

$F$. tularensis and A. phagocytophilum DNA was not detected either in rodents or in ticks. A total of 143 blood samples were collected from 101 Apodemus spp. and 42 M. glareolus individuals. Seven Apodemus spp. and five M. glareolus were positive for B. burgdorferi s.l.; only two samples, both belonging to Apodemus spp., were positive for C. burnetii. Detailed results of real-time PCR tests on rodent blood samples are summarized in Table 4, and the localization of positives sites within the study area is shown in Figure 1.

\section{Discussion}

This is the first report on tick-borne pathogens in the area of "Gran Sasso e Monti della Laga" National Park. Moreover, we provide one of the few examples of studies on the ecology of TBD where wild rodents were not euthanized. The investiga-

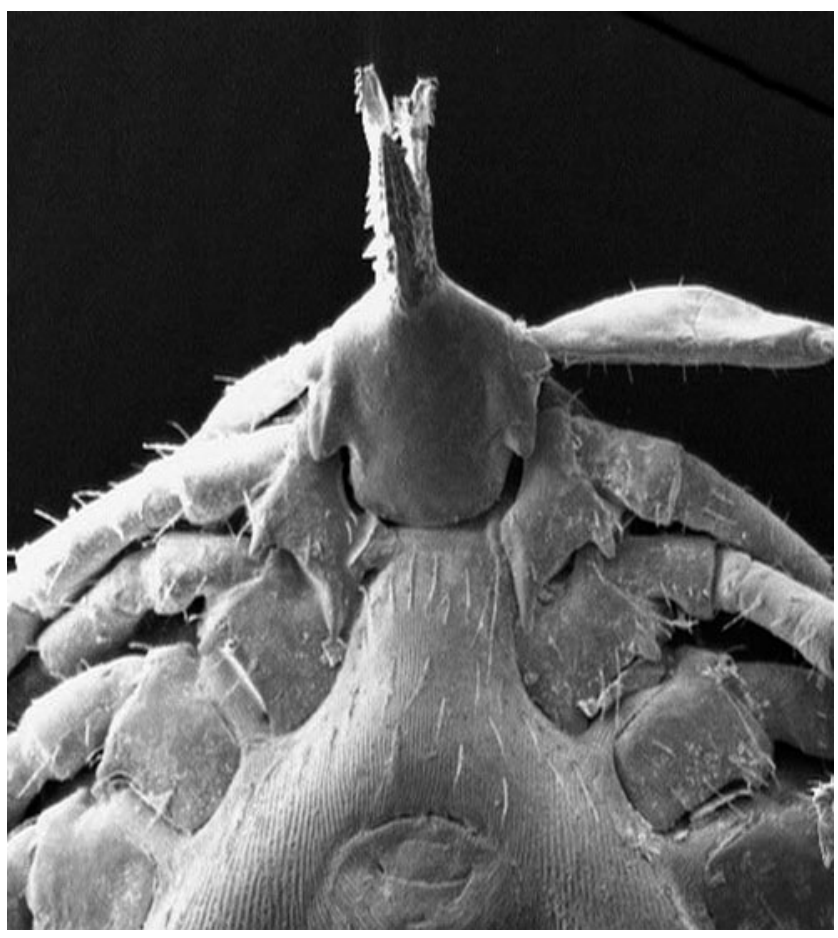

FIG. 5. SEM of an Ixodes acuminatus tick collected from a rodent. Note the long, thin, straight inner spur of coxa I extending beyond anterior margin of coxa II, the triangular auriculae, and the fusiform hypostoma with thinly pointed tips.
Table 3. Results of Real-Time PCR Tests on Pools of Ticks COLleCted FROM Wild Rodents to Detect the Presence of Pathogens

\begin{tabular}{llcc}
\hline & & \multicolumn{2}{c}{ Positive pools } \\
\cline { 3 - 4 } Tick species & \multicolumn{1}{c}{ Rodent host } & $\begin{array}{c}\text { Borrelia } \\
\text { burgdorferi s.l. }\end{array}$ & $\begin{array}{c}\text { Coxiella } \\
\text { burnetii }\end{array}$ \\
\hline I. acuminatus & Apodemus spp. & 5 & 4 \\
I. ricinus & Myodes glareolus & 3 & 2 \\
& Apodemus spp. & 1 & 4 \\
R. turanicus & Myodes glareolus & 1 & - \\
& Apodemus spp. & 2 & - \\
Ixodes sp. & Myodes glareolus & 1 & - \\
All species & Apodemus spp. & - & - \\
\multirow{2}{*}{ Total } & Myodes glareolus & - & 9 \\
& Myodemus spp. & 8 & 2 \\
\hline
\end{tabular}

tion on TBD ecology often requires fatal practices for small mammal fauna, because trapped animals are usually euthanized before being processed for DNA extraction and PCR aimed to detect pathogens (Liz et al. 2000, Smetanová et al. 2006, Barandika et al. 2007). Although potential vectors and reservoirs for pathogens, small mammals still constitute an important component of natural ecosystems as preys for other vertebrates or seed dispersers. A high mortality may alter natural processes and should be avoided whenever possible. In our study, we used a poorly invasive approach on live rodents that allowed us not to impact this key component of natural communities. By spotting a few drops of blood from live animals on FTA gene cards, we could collect important information on their role as reservoirs for tick-borne pathogens. With our preliminary study, we could not evaluate the sensitivity of this method, but we demonstrated the environmental suitability of the area in supporting both cycles of Lyme disease and Q fever.

The specific considerations for each disease follow.

\section{Lyme disease}

Real-time PCR tests detected the presence of the etiological agent (B. burgdorferi s.1.) in ticks and blood samples. Furthermore, because transovarian transmission does not occur in the Lyme disease cycle, it is likely that rodents play the role of reservoir, as supported in the literature. The detection of B. burgdorferi s.l. in $R$. turanicus larvae confirms the presence of this agent in the environment, although this tick is not recognized as a competent vector.

Considering that eight samples of I. acuminatus were positive for $B$. burgdorferi s.l., further studies should be performed to assess the role of I. acuminatus in maintaining the ecological cycle of Lyme disease in the environment. In fact, little is known on the eco-biology of this endophilous and monotrophic species compared to the main European vector I. ricinus. Moreover, finding B. afzelii confirms that wild rodents play the role of reservoir in maintaining the ecological cycle of this particular genospecies. The prevalence of Lyme disease spirochetes found in rodents in the Abruzzi Region is lower (8.39\%) than those reported in endemic areas (i.e., 24\% in Austria, Khanakah et al. 2006; $16 \%$ in Czech Republic, Kybicová et al. 2008), whereas it is 
Table 4. Results of Real-Time PCR on Wild Rodent Blood Samples to Detect The PRESEnce of Pathogens

\begin{tabular}{lccccc}
\hline & \multicolumn{2}{c}{ Borrelia burgdorferi s.1. } & & \multicolumn{2}{c}{ Coxiella burnetii } \\
\cline { 2 - 3 } Rodent species & $\begin{array}{c}\text { Positives/ } \\
\text { examined }\end{array}$ & $\begin{array}{c}\text { Estimated } \\
\text { prevalence (95\% CI) }\end{array}$ & & $\begin{array}{c}\text { Positives/ } \\
\text { examined }\end{array}$ & $\begin{array}{c}\text { Estimated } \\
\text { prevalence (95\% CI) }\end{array}$ \\
\hline Apodemus spp. & $7 / 101$ & $6.93 \%(3.45-13.63 \%)$ & & $2 / 101$ & $1.98 \%(0.61-6.90 \%)$ \\
Myodes glareolus & $5 / 42$ & $11.90 \%(5.30-25.08 \%)$ & & $0 / 42$ & $0 \%(0-6.73 \%)$ \\
Total & $12 / 143$ & $8.39 \%(4.89-14.10 \%)$ & & $2 / 143$ & $1.40 \%(0.43-4.93 \%)$ \\
\hline
\end{tabular}

CI, confidence interval.

similar to that observed in the Mediterranean countries (i.e., $6.3 \%$ in Spain, Barandika et al. 2007).

In our preliminary study, M. glareolus was associated with a higher prevalence of infection compared to Apodemus spp., suggesting that species-specific differences can occur in the role of rodents as reservoirs, although this difference was not significant as shown by the overlapping confidence intervals (Table 4). Our results are consistent with the work of Humair et al. (1999), who also found lower infection prevalence in Apodemus mice, probably related to their stronger immune response to B. burgdorferi s.l. infection. Further studies should be carried out to evaluate the role of different congeneric species, such as A. sylvaticus and A. flavicollis, having contrasting ecological and habitat requirements and that are likely to contribute differently to the maintenance of this pathogen in the environment.

\section{$Q$ fever}

Tick samples were found positive by real-time PCR, showing the presence of the etiological agent in the environment. The percentage difference between the level of infection in rodents and ticks is probably due to the transovarian transmission of $C$. burnetii that can occur in ticks. Several serological studies demonstrated the circulation of $C$. burnetii in wild and domestic animals, whereas there are few studies showing the presence of $C$. burnetii in small wild mammals. In Spain, as an example, the pathogen was recently detected in Mus musculus and A. sylvaticus captured in a sheep farm with previous reports of abortion (Barandika et al. 2007). Therefore, these rodents might have acquired the infection by direct contact with infected sheep rather than in natural foci. C. burnetii was not detected in rodent organs in southern Germany in a study carried out by Pluta et al. (2010). Coxiella prevalence (18\%) at the Sino-Russian border was recently detected by checking rodent organs by PCR (Liu et al. 2013), whereas a higher prevalence $(83.3 \%$ and $76.1 \%)$ was detected in two different rodent species in Canadian Natural Environment Park (Thompson et al. 2012). The detection of C. burnetii in Apodemus spp. demonstrates that rodents are susceptible to C. burnetii infection and may play a role in the natural maintenance of $\mathrm{Q}$ fever in wild cycle in the studied area.

As for B. burgdorferi s.l., with our preliminary study, we failed to find significant differences between the infection prevalence in Apodemus spp. and M. glareolus, even though results seem to suggest a higher infection prevalence in Apodemus spp. Further studies should be carried out to investigate species-specific differences in the role of wild rodents as reservoirs for this pathogen. Species differences in infection prevalence, in fact, could be related to different life history traits, such as social and mating systems. C. burnetii is not only transmitted by ticks, but also by aerosols and contact with infected feces and birth products, routes that are more effective with frequent relationship between individuals of a social population. Reproductive behavior can also affect the rate of transmission, leading to a different prevalence according to species. Furthermore, species-specific ecological and habitat requirement can determine drastically different probabilities of contact with other hosts and vectors of TBDs, so that infection probability can be very different even between species of the same genus.

In their study on tick-rodent transmission of B. afzelii, Humair et al. (1999) found that Apodemus spp. and M. glareolus were associated with different infection prevalence, infectivity, and moulting success for ticks, thus suggesting that they play different roles in the process of maintaining the pathogen in the environment. Therefore, several biological, ecological, and immunological aspects should be considered while evaluating the efficiency of a rodent species as a reservoir for TBDs. C. burnetii was largely investigated in Italy in ruminant farms by serology and molecular methods (Martini et al. 1994, Masala et al. 2004, Parisi et al. 2006, Perugini et al. 2009), whereas only Mantovani (1950) described a serosurveillance study in the Abruzzi Region, reporting a seroprevalence amongst small ruminants between $11 \%$ and $28 \%$. Thus, to date the present work is the first report in Italy that confirms the presence of $C$. burnetii DNA in wild rodents. Genotyping of rodent-associated strains will be the next step in studying the ecology of Coxiella, considering the recent detection of novel genotypes circulating in the Abruzzi Region (Di Domenico et al. 2014), and in assessing the risk of $\mathrm{Q}$ fever for livestock and humans.

\section{Human granulocytic anaplasmosis}

Negative results seem to suggest the absence of circulation of an A. phagocytophilum rodent-associated genotype in the area. Further investigation and genotyping is needed to better understand the ecological cycle of this pathogen.

A few authors suggest the role played by rodents as reservoirs of A. phagocytophilum, as supported by reported infections in organs (Liz et al. 2000, Woldehiwet 2006). However, the detection of pathogens in organs only proves that the host is a carrier. To be considered as an actual reservoir, hosts should show bacteremia and should be infective for ticks. Very few studies have focused their investigation on Anaplasma infection in rodent blood until recently. Baráková et al. (2014) reported a very low prevalence in wild rodents $(0.3 \%)$, suggesting a low 
ability to transmit the pathogen. Similarly, in the United States, white-footed mice are considered a poor reservoir for A. phagocytophilum because infection in mice is transient, possibly resulting from host immunity (Jin et al. 2012). Moreover, a xenodiagnosis experiment carried out on Apodemus and Myodes species also suggests that these rodents do not transmit A. phagocytophilum (Burri et al. 2014). On the other hand, A. phagocytophilum DNA is frequently detected in ticks and wild ruminants during wildlife health monitoring activities carried out in the Abruzzi Region (Pascucci et al. 2013), and the detection of specific antibodies in domestic animals is common.

\section{Tularemia}

F. tularensis was not detected in wild rodents and ticks by molecular tests, suggesting its absence from the area. Furthermore, the pathogen has never been detected during routine wildlife health monitoring and human clinical cases have never been reported in the Abruzzi Region, although serological positive reactions to an agglutination test are sporadically registered in hunted wildlife. The complexity of the $F$. tularensis life cycle and the possibility of chronic and acute fatal infections in rodents and lagomorphs (Rossow et al. 2014) suggest a thorough evaluation of the data and that further investigation should be performed to find other potential sources of infection in the area.

\section{Conclusions}

Several studies have demonstrated that the intricate relationships between biotic and abiotic factors in the ecosystem are able to shape the transmission patterns of specific pathogens, affecting the risk for humans. Our findings, although preliminary, provide completely new information for the "Gran Sasso e Monti della Laga" National Park and for central Italy, and act as a starting point for further research. The study area seems to have suitable conditions for supporting high biodiversity and including all the elements of the complex life cycle of the tick-borne pathogens (reservoir and vertebrate hosts, ticks as vectors). Further research should be carried out to define possible risk factors for humans.

\section{Acknowledgments}

Authors would like to thank Dr. Osvaldo Locasciulli of the "Gran Sasso e Monti della Laga" National Park and Dr. Javier Bravo of Sapienza University of Rome for their support, as well as Dr. Anna Rita D'Angelo and Dr. Carla Ippoliti of Istituto Zooprofilattico Sperimentale dell'Abruzzo e del Molise "G. Caporale" for SEM of I. acuminatus and for building maps, respectively.

The study was funded by Italian Ministry of Health (IZAM0306/RC).

\section{Author Disclosure statement}

No competing financial interests exist.

\section{References}

Baráková I, Derdáková M, Carpi G, Rosso F, et al. Genetic and ecologic variability among Anaplasma phagocytophilum strains, northern Italy. Emerg Infect Dis 2014; 20:1082-1085.
Barandika JF, Hurtado A, García-Esteban C, Gil H, et al. Tickborne zoonotic bacteria in wild and domestic small mammals in northern Spain. Appl Environ Microbiol 2007; 73:61666171.

Beltrame A, Ruscio M, Arzese A, Rorato G, et al. Human granulocytic anaplasmosis in northeastern Italy. Ann NY Acad Sci 2006; 1078:106-109.

Burri C, Schumann O, Schumann C, Gern L. Are Apodemus spp. mice and Myodes glareolus reservoirs for Borrelia miyamotoi, Candidatus Neoehrlichia mikurensis, Rickettsia helvetica, R. monacensis and Anaplasma phagocytophilum? Ticks Tick Borne Dis 2014; 5:245-251.

Caporale G, Mantovani A. Q-fever in central Italy. J Am Vet Med Assoc 1951; 119:438-439.

Castro R, Campanella G, Gullino E, Bianconi E, et al. Tularemia: Considerations on a new case in the Monte Amiata. Minerva Med 1999; 90:81-83.

Courtney JW, Kostelnik LM, Zeidner NS, Massung RF. Multiplex real-time PCR for detection of Anaplasma phagocytophilum and Borrelia burgdorferi. J Clin Microbiol 2004; 42:3164-3168.

Di Domenico M, Curini V, De Massis, F, Di Provvido A, et al. Coxiella burnetii in Central Italy: Novel genotypes are circulating in cattle and goats. Vector Borne Zoonotic Dis 2014; 14:710-715.

Fabbi M, Messeri D, Vicari N, Marino Merlo L, et al. An outbreak of tularemia in Tuscany, central Italy, linked to a natural spring water. 6th International Conference on Tularemia, Tularemia Network, 2009.

Fazii P, Ballone E, Ippolito N, Cosentino L, et al. Survey of Lyme disease in Abruzzo (Italy). Int $\mathbf{J}$ Immunopathol Pharmacol 2000; 13:151-156.

Gern L. Borrelia burgdorferi sensu lato, the agent of Lyme borreliosis: Life in the wilds. Parasite 2008; 15:244-247.

Greco D, Allegrini G, Tizzi T, Ninu E, et al. A waterborne tularemia outbreak. Eur J Epidemiol 1987; 3:35-38.

Humair PF, Rais O, Gern L. Trasmission of Borrelia afzelii from Apodemus mice and Clethrionomys voles to Ixodes ricinus ticks: Differential transmission patern and overwintering maintenance. Parasitology 1999; 118:43-48.

Jin H, Wei F, Liu Q, Qian J. Epidemiology andc of human granulocytic anaplasmosis: A aystematic review. Vector Borne Zoonotic Dis 2012; 12:269-274.

Kaysser P, Seibold E, Mätz-Rensing K, Pfeffer M, et al. Reemergence of tularemia in Germany: Presence of Francisella tularensis in different rodent species in endemic areas. BMC Infect Dis 2008; 8:157.

Khanakah G, Kocianova E, Vyrostekova V, Rehacek J, et al. Seasonal variations in detecting Borrelia burgdorferi sensu lato in rodents from north eastern Austria. Wien Klin Wochenschr 2006; 118:754-758.

Kybicová K, Kurzová Z, Hulínská D. Molecular and serological evidence of Borrelia burgdorferi sensu lato in wild rodents in the Czech Republic. Vector Borne Zoonotic Dis 2008; 8:645652.

Liu L, Baoliang X, Yingqun F, Ming L, et al. Coxiella burnetii in rodents on Heixiazi Island at the Sino-Russian Border. Am J Trop Med Hyg 2013; 88:770-773.

Liz JS, Anderes L, Sumner JW, Massung RF, et al. PCR Detection of granulocytic ehrlichiae in Ixodes ricinus ticks and wild small mammals in western Switzerland. J Clin Microbiol 2000; 38:1002-1007.

Manilla G. Fauna d'Italia-Ixodida. Italy: Edizioni Calderini de Il Sole 24 ORE Edagricole, 1998. 
Mantovani 1950. Ricerche sulla epizoologia della Febbre Q in rapporto agli spostamenti dei greggi ovini e caprini. Convegno di Milano, Atti della Società Italiana delle Scienze Veterinarie 1950; 4:601-608.

Martini M, Baldelli R, Paulucci De Calboli L. An epidemiological study on Q fever in the Emilia-Romagna Region, Italy. Zentralbl Bakteriol 1994; 280:416-422.

Masala G, Porcu R, Sanna G, Chessa G, et al. Occurrence, distribution, and role in abortion of Coxiella burnetii in sheep and goats in Sardinia, Italy. Vet Microbiol 2004; 19:301-305.

Ministry of Health (Italy) (Ministero della Salute). Malattie trasmesse da zecche: Cenni di epidemiologia-misure di prevenzione. Circolare n. 10 del 13 luglio 2000. Italy, Rome, 2000, 12 pp. Available at www.salute.gov.it/imgs/C_17_ normativa_82_allegato.pdf Accessed March 17, 2015.

Nigrovic LE, Wingerter SL. Tularemia. Infect Dis Clin North Am 2008; 22:489-504.

Panning M, Kilwinski J, Greiner-Fischer S, Peters M, et al. High throughput detection of Coxiella burnetii by real-time PCR with internal control system and automated DNA preparation. BMC Microbiol 2008; 8:77.

Parisi A, Fraccalvieri R, Cafiero M, Miccolupo A, et al. Diagnosis of Coxiella burnetii-related abortion in Italian domestic ruminants using single-tube nested PCR. Vet Microbiol 2006; 118:101-106.

Pascucci I, Cammà C. Lyme disease and the detection of Borrelia burgdorferi genospecies in Ixodes ricinus ticks from central Italy. Vet Ital 2010; 46:173-188.

Pascucci I, Di Sabatino D, Angelucci S, Dall'Acqua F, et al. Diagnostic findings in a young roe deer (Capreolus capreolus, Linnaeus 1758) with neurological signs. $X^{\text {th }}$ National Congress of Italian Association of Veterinary Pathologist (AIPVet), May 29-31, 2013; Giulianova Lido (TE)-Italy.

Pecchioli E, Hauffe HC, Tagliapietra V, Bandi C, et al. Genospecies of Borrelia burgdorferi sensu lato in Ixodes ricinus ticks from the Autonomous Province of Trento, Italy. Int J Med Microbiol 2007; 297:53-59.

Perugini AG, Capuano F, Esposito A, Marianelli C, et al. Detection of Coxiella burnetii in buffaloes aborted fetuses by IS111 DNA amplification: A preliminary report. Res Vet Sci 2009; 87:189-191.

Pluta S, Hartelt K, Oehme R, Mackenstedt U, et al. Prevalence of Coxiella burnetii and Rickettsia spp. in ticks and rodents in southern Germany. Ticks Tick Borne Dis 2010; 1:145-147.
Ragagli C, Bertolotti L, Giacobini M, Mannelli A, et al. Transmission dynamics of Borrelia lusitaniae and Borrelia afzelii among Ixodes ricinus, lizards, and mice in Tuscany, central Italy. Vector Borne Zoonotic Dis 2011; 11:21-28.

Rijpkema SG, Molkenboer MJ, Schouls LM, Jongejan F, et al. Simultaneous detection and genotyping of three genomic groups of Borrelia burgdorferi sensu lato in Dutch Ixodes ricinus ticks by characterization of the amplified intergenic spacer region between $5 \mathrm{~S}$ and $23 \mathrm{~S}$ rRNA genes. J Clin Microbiol 1995; 33:3091-3095.

Rizzoli A, Hauffe HC, Carpi G, Vourc'h GI, et al. Lyme borreliosis in Europe. Eurosurveillance 2011; 16:pii = 19906.

Rossow H, Forbes KM, Tarkka E, Kinnunen PM, et al. Experimental infection of voles with Francisella tularensis indicates their amplification role in tularemia outbreaks. PLoS One 2014; 9:e108864.

Smetanová K, Schwarzová K, Kocianová E. Detection of Anaplasma phagocytophilum, Coxiella burnetii, Rickettsia spp., and Borrelia burgdorferi s.l. in ticks, and wild-living animals in western and middle Slovakia. Ann NY Acad Sci 2006; 1078:312-315.

Stuen S, Granquist EG, Silaghi C. Anaplasma phagocytophilum-a widespread multi-host pathogen with highly adaptive strategies. Front Cell Infect Microbiol 2013; 3:31.

Thompson M, Mykytczuk N, Gooderham K, Schulte-Hostedde AI. Prevalence of the bacterium Coxiella burnetii in wild rodents from a Canadian natural environment park. Zoonoses Public Health 2012; 59:553-560.

Versage JL, Severin DDM, Chu MC, Petersen JM. Development of a multitarget real-time Taqman PCR assay for enhanced detection of Francisella tularensis in complex specimens. J Clin Microbiol 2003; 41:5492-5499.

Woldehiwet Z. Anaplasma phagocytophilum in Ruminants in Europe. Ann NY Acad Sci 2006; 1078:446-460.

Address correspondence to: Ilaria Pascucci Istituto Zooprofilattico Sperimentale dell'Abruzzo $e$ del Molise "G. Caporale" Campo Boario 64100 Teramo Italy

E-mail: i.pascucci@izs.it 